\title{
How to treat patients that do not tolerate continuous positive airway pressure
}

\section{Educational aims}

1 To outline recommendations concerning the proper management of obstructive sleep apnoea/ hypopnoea syndrome (OSAHS) patients that cannot be treated adequately with continuous positive airway pressure (CPAP) due to intolerance, poor compliance or CPAP refusal.

1 To provide information about the selection of appropriate patients for alternative non-CPAP treatment modalities.

I To better understand the different aspects of OSAHS treatment with oral appliances, including indications, contraindications, medical work-up and clinical protocol, and expected short and long-term results.

1 To discuss the different surgical options for the treatment of OSAHS and to provide information on the important issue of a proper patient selection for upper airway surgery, as most OSAHS surgical outcomes are associated with the preoperative assessment of the level(s) of upper airway collapse. Finally, to present future perspectives in sleep apnoea surgery.

\section{Summary}

The effectiveness of continuous positive airway pressure (CPAP) is potentially high for the treatment of obstructive sleep apnoea/hypopnoea syndrome (OSAHS), but accounting for the relatively low acceptance and compliance, and correcting for sleep time, its actual effect and use, the adjusted CPAP effectiveness remains relatively low.

Oral appliance therapy has emerged as a noninvasive alternative to CPAP in subjects with OSAHS who do not tolerate or comply with CPAP. Surgical procedures can be performed successfully in carefully selected patients. Moreover, concerning the surgical treatment options, it appears from the available evidence that maxillomandibular advancement is a safe and highly effective surgical treatment modality for OSAHS that should be indicated more readily in clinical practice.

Two methods of pre-treatment airway evaluation will be discussed. First, newer technologies using imaging techniques coupled with computational fluid dynamics methods allow investigation of the flow characteristics and aerodynamic forces within the upper airway of the OSAHS patient. Secondly, routine application of drug-induced sleep endoscopy to assess the site(s) of flutter and upper airway obstruction during druginduced sleep can increase the success rate of both upper airway surgery and oral appliance therapy.

Obstructive sleep apnoea/hypopnoea syndrome (OSAHS) is the most common type of sleep-disordered breathing (SDB) and is characterised by repetitive episodes of upper airway obstruction that occur during sleep, usually associated with a reduction in blood
O.M. Vanderveken ${ }^{1}$

A. Hoekema ${ }^{2}$

${ }^{1}$ Dept of ENT, Head and Neck Surgery, University of Antwerp, University Hospital Antwerp, Antwerp, Belgium

${ }^{2}$ Dept of Oral and Maxillofacial Surgery, University Medical Center Groningen, University of Groningen, Groningen, The Netherlands

\section{Correspondence}

O.M. Vanderveken, MD, PhD Department of ENT, Head and Neck Surgery,

University of Antwerp

University Hospital Antwerp

Wilrijkstraat 10

BE-2650 Edegem

Antwerp

Belgium

olivier.vanderveken@uza.be
HERMES syllabus link: module E1.6 
oxygen saturation and sleep fragmentation [1]. OSAHS is a highly prevalent disease, and has been recognised as an important health problem with relevant long-term consequences leading to a significant morbidity and excess mortality [2]. The major risk factor in OSAHS patients is the strong and independent association between OSAHS and systemic hypertension, leading to cardio- and cerebrovascular morbidity [3-7].

The management of SDB consists of general and specific measures. General measures include behavioral strategies, such as weight loss, positional therapy and avoidance of alcohol and sedatives before bedtime [8]. The standard treatment for moderate-to-severe OSAHS is application of nasal continous positive airway pressure (CPAP) [9]. Oral appliance therapy has emerged as a noninvasive alternative to CPAP, and is indicated for patients with mild-tomoderate OSAHS, and in subjects with OSAHS who do not tolerate or comply with CPAP $[10,11]$. Mandibular repositioning appliances (MRAs), which are worn intraorally at night to advance the mandible, are currently the most common class of oral appliances used to treat OSAHS $[12,13]$. MRAs and CPAP are the two treatments for OSAHS whose effects on cardiovascular end-points have been assessed in randomised trials [14]. The indications for sleep apnoea surgery are controversial, and the role of upper airway surgery in obese OSAHS patients is not well established [15-17]. In obese sleep apnoea patients, bariatric surgery may well be the most causal and effective approach [18].

CPAP has been accepted as the treatment of choice for OSAHS patients with moderate-tosevere disease. Nasal CPAP, acting as a "pneumatic splint" preventing upper airway collapse, was initially described by Suluvan et al. [9] in 1981. Since its initial description, the effectiveness of CPAP has been demonstrated in several studies [19-22]. However, despite the considerable improvement of CPAP technology over the

Table 1 Most common CPAP-related problems.

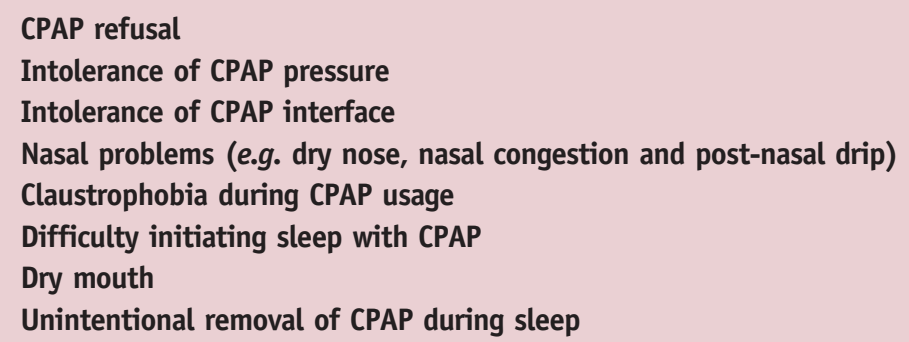

years, compliance and long-term use with CPAP are still rather low [23-26] and the acceptance rate of CPAP therapy remains a problem. During the follow-up of the patient, sleep clinicians and other personnel at the sleep laboratory should monitor CPAP usage. Reasons for problems with CPAP vary among patients. When problems with CPAP therapy are encountered, patients can be advised of possible solutions to overcome the reported hurdles $[27,28]$. The most common CPAP-related problems and reasons for CPAP discontinuation are listed in table $1[24,27]$.

It should be emphasised that it is important to provide intensive support of patients that report these CPAP-related problems. A detailed exploration of every CPAP-related problem should be provided in a multidisciplinary setting at the sleep laboratory. Careful and detailed attention should be paid to a CPAP-related problem before CPAP failure is concluded too readily.

Nasal problems are common CPAP-related problems (table 1). To overcome nasal symptoms that hinder CPAP use and compliance, humidified CPAP and/or treatment with topical nasal steroid sprays are often prescribed. In a recent study, RYAN et al. [29] demonstrated that the addition of a heated humidifier, but not application of nasal steroids, decreased the frequency of nasal symptoms in unselected OSAHS patients initiating CPAP therapy. In that study, however, compliance and quality of life remained unaltered with these interventions [29]. Isolated nasal surgery will only seldomly resolve OSAHS, but nasal surgical procedures can help to improve CPAP usage in the case of nasal complaints [30].

It seems that the patient's initial impression of CPAP is an important predictor of long-term adherence and that treatment compliance increases with more severe sleepiness [23]. Nevertheless, since CPAP decreases the excessive healthcare costs for cardiovascular disease and other sequelae of SDB, CPAP therapy for patients with OSAHS has a costeffectiveness that is in line with that of other commonly funded healthcare interventions [7, 31]. Moreover, the costeffectiveness of early OSAHS management is related with OSAHS severity [32].

In obese patients, a considerable reduction of CPAP pressure requirements occurs after bariatric surgery [33]. The use of autotitrating CPAP, providing pressure modification, improves average machine use compared to CPAP [34]. Furthermore, the effective CPAP pressure may be lowered substantially by combining this therapeutic modality with an MRA [35] and by doing so, therapeutic compliance may be increased, 
resulting in a more efficacious treatment out come of CPAP. However, before CPAP-MRA combination therapy can be advised on a standard basis, larger patient populations need to be studied in order to support the efficacy and costeffectiveness of this therapeutic regime on both short- and long-term outcomes.

In conclusion, effectiveness of CPAP is potentially high, but accounting for the relatively low acceptance and compliance, and correcting for sleep time, its actual effect and use, adjusted CPAP effectiveness of only $50 \%$ is observed [26].

\section{Non-CPAP treatment options}

Although CPAP is a highly successful treatment for OSAHS when used properly and consistently, its clinical success is limited by the fact that not all patients can tolerate this treatment or are compliant with it. Efficacious alternative therapies are still remarkably few in number [25].

Oral appliances, such as MRAs, are indicated for use in patients with mild-to-moderate OSAHS who prefer them to CPAP therapy, or who do not respond to, are not appropriate candidates for, or who fail treatment attempts with CPAP [11]. Oral devices were recently shown to improve arterial hypertension in OSAHS patients [36].

Surgical procedures can be performed successfully in well-selected patients and when a tailored approach is used. The exact indications for more novel surgical techniques, such as electrical stimulation of the hypoglossal nerve, a tongue anchor for tongue advancement or transoral robotic tongue base resection, are still to be determined, although preliminary results seem to be promising [37-39].

\section{Oral appliance therapy}

Oral appliance therapy has emerged as a noninvasive alternative to CPAP for the treatment of snoring and OSAHS $[40,41]$. Mandibular advancement devices or MRAs (fig. 1), which are worn intraorally at night to advance the lower jaw, are currently the most widespread and evaluated type of oral appliance used to treat OSAHS [10]. Recent studied suggest that MRAs are an effective treatment for OSAHS in clinical practice $[40,42]$. MRAs reduce the severity of OSAHS to a lesser or a similar extent than CPAP. Nevertheless, MRAs appear to have higher compliance rates and a higher patient preference with fewer sideeffects and greater satisfaction when compared with CPAP therapy $[43,44]$. However, as CPAP is the more efficacious treatment for OSAHS, it is recommended that CPAP is prescribed before oral appliance therapy for the treatment of patients with severe OSAHS $[45,46]$.

Oral appliance therapy may be a firstline treatment in snorers with or without excessive daytime sleepiness [42, 47-48]. The 2005 update of the practice parameters published by the American Academy of Sleep Medicine [11], recommends oral appliance therapy for patients with mild-to-moderate OSAHS who prefer this treatment to CPAP. Patients who prefer oral appliances include those whose apnoeas do not improve with CPAP, who fail treatment attempts with CPAP, perhaps due to noncompliance, or who are not appropriate candidates for CPAP for other reasons [11]. In addition, oral appliance therapy may be a second-line treatment in severe OSAHS patients that have failed CPAP therapy [38]. Treatment with MRAs may also be considered as a temporary alternative for CPAP (e.g. frequent flyers) [49]. Finally, oral appliances can be a rescue treatment after upper airway surgery failure (e.g. uvulopalatopharyngoplasty; UPPP) (table 2) [50].

When considering oral appliance therapy, several dental exclusion criteria should be taken into account. In up to onethird of cases, an MRA cannot be used because of dental contraindications [51]. Factors for consideration include (extensive) periodontal disease and dental decay, active temporomandibular joint disorders, and restrictions in mouth opening (i.e. $<25 \mathrm{~mm}$ ) or advancement of the mandible (i.e. $<5 \mathrm{~mm}$ ). In the majority of cases, however, there is an insufficient number of teeth to support and retain the appliance [51]. This is especially the case in edentulous patients. Although some consider a minimum of ten sound teeth in each of the maxillary and mandibular arches a requisite in MRA therapy, the location, rather than the number, of teeth may be more important (i.e. posterior teeth provide more adequate retention) [51]. In order to stabilise and retain an MRA in (partially) edentulous patients, osseointegrated dental implants may be used [52]. Because this technique requires a longer period before therapy may be initiated, it is generally only worth considering in selected patients. The absolute contraindications that should be considered in overall evaluations of oral appliance therapy are listed in table 3.

In addition, as with CPAP, nasal obstruction or allergic rhinitis may be relative contraindications, 

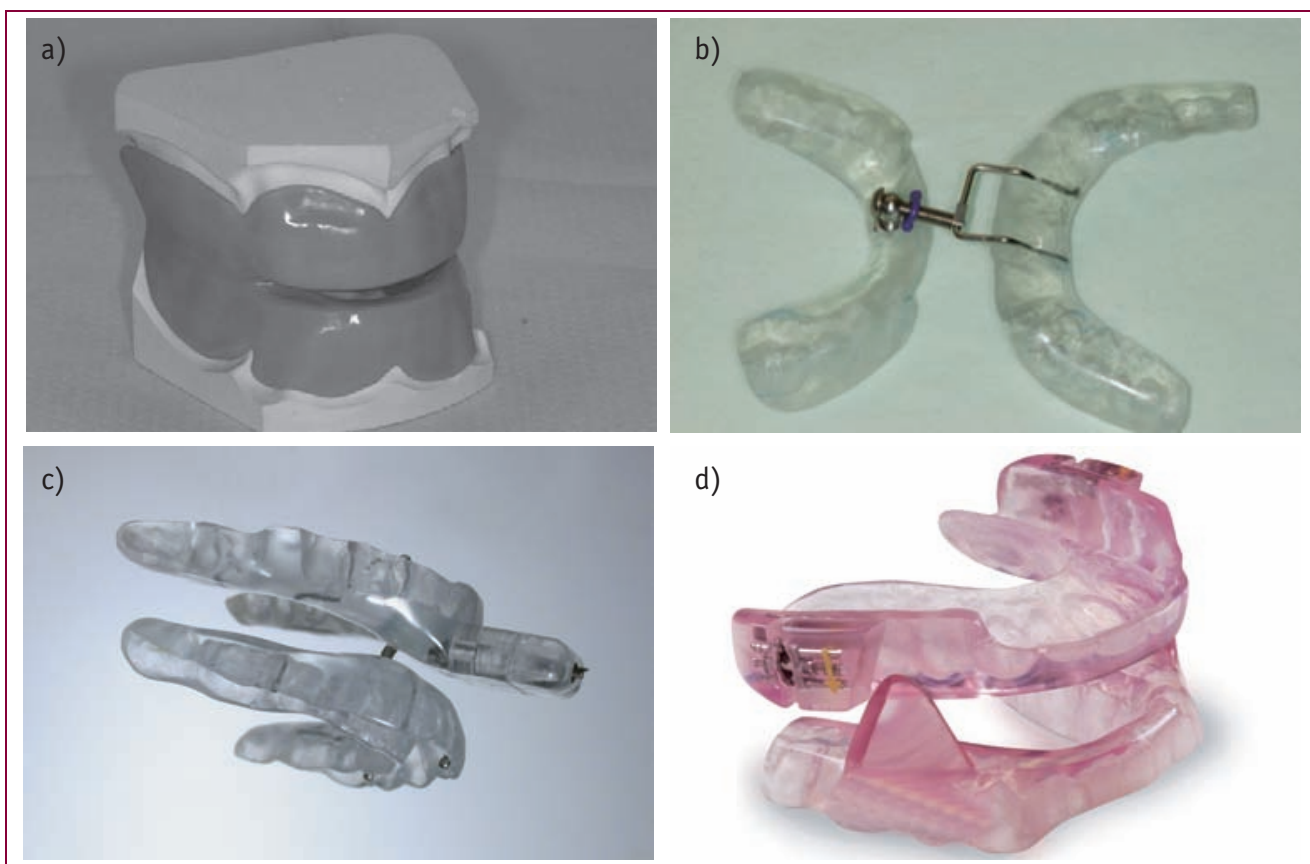

d)

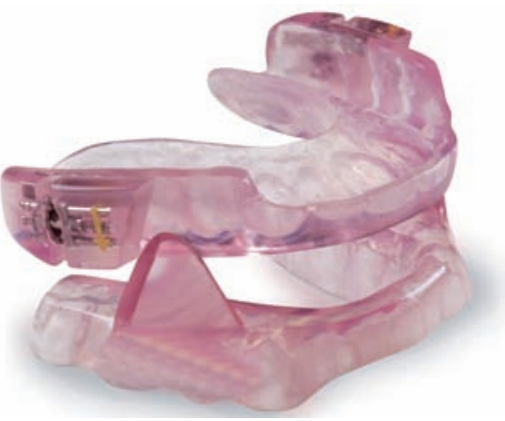

\section{Figure 1}

Examples of some custom-made mandibular repositioning appliances (MRAs) used in clinical practice: a) a homemade monobloc appliance; b) the Butterfly MRA (Respident, Antwerp, Belgium), a duobloc MRA with attachments for adjustment of mandibular protrusion in the frontal teeth area; c) the Thornton Adjustable Positioner (TAP) appliance (Airway Management, Inc., Texas, USA), composed of both mandibular and maxillary arches with a screw mechanism in the upper arch to allow for the advancement of the mandible; and d) a custom-made two-piece MRA with two lateral screw devices that permit incremental protrusion of the mandible (SomnoDent MAS; SomnoMed Ltd, New South Wales, Australia).

and should be assessed and treated in selected patients [53]. Finally, oral appliance therapy can only be prescribed in cooperative patients that

Table 2 Candidates for mandibular repositioning appliance (MRA) treatment

Snorers with or without excessive daytime sleepiness

Patients with mild-to-moderate OSAHS who prefer MRA to CPAP therapy

Patients with severe OSAHS who have failed CPAP therapy

OSAHS patients that need a temporary alternative for CPAP

OSAHS patients that need a rescue treatment after upper airway surgery failure

OSAHS: obstructive sleep apnoea/hypopnoea syndome; CPAP: continuous positive airway pressure.

\section{Table 3. Absolute contraindications for mandibular repositioning appliance treatment}

Extensive periodontal problems (e.g. tooth mobility)

Extensive dental decay

Active temporomandibular disorders

Limited mandibular protrusive capacity $(<5 \mathrm{~mm})$

Limitations in jaw opening $(<25 \mathrm{~mm})$

Insufficient number of teeth to support the device are motivated to wear the device on a regular basis [53]. When no contraindications for oral appliance therapy are present, plaster models and a bite registration are obtained, as appropriate for the specific oral appliance [53]. Once optimal fit is obtained and efficacy of an oral appliance has been shown by follow-up sleep study, recall dental appointments are scheduled every 6 months for the first year, and at least annually thereafter [8]. Besides these regular dental follow-up visits, patients should also return for periodic follow-up visits with the referring physician. Should oral appliance therapy cause discomfort or fail during the follow-up period, treatment should be adjusted or patients may discontinue therapy and start with an alternative treatment.

Most studies suggest that an MRA derives its therapeutic effect mainly from the amount of mandibular advancement imposed by the appliance [33]. However, in some OSAHS patients, the number of upper airway obstructions may increase when the mandible is protruded towards its maximum [33]. Determination of the amount of mandibular advancement required to prevent snoring or OSAHS in a 
given patient is, therefore, generally a matter of trial and error. Treatment usually commences with an adaptation period (generally 1-2 weeks) that is followed by a titration period (generally 1-2 months). Titration of the appliance should be aimed at accomplishing the amount of mandibular advancement that yields a resolution of symptoms with minimum discomfort and sideeffects. However, details of the titration process, including the initial and target degree of mandibular advancement, are highly variable between different types of appliances and practitioners. The need for an acclimatisation period is considered a drawback of oral appliance therapy, particularly in situations where rapid initiation of treatment is required (e.g. severe OSAHS). Several studies have reported on the feasibility of a singlenight titration of an MRA using remotely controlled appliances [40, 54]. This technique may offer the advantage of directly ascertaining the likelihood of treatment success, as well as the amount of mandibular advancement required in an individual patient. However, the difficulty of achieving the required mandibular advancement without discomfort on the first night and the laborious nature of the titration may limit widescale application of this technique.

Custom-made oral appliances are generally thought to have a better overnight retention within the oral cavity, and provide a higher level of comfort and efficacy (fig. 1) [40, 41]. Thermoplastic devices are not recommended as a therapeutic option nor to be used as a screening tool to find good candidates for oral appliance therapy [12]. However, as there is a huge variety of available devices with different designs, and, in the absence of a sufficient amount of studies comparing different devices, the results from these trials cannot be extrapolated to all types of devices. Therefore, the conclusions should be limited to the devices tested and may not apply to other types of oral appliances presently available for the treatment of snoring and OSAHS $[55,56]$.

There is growing evidence that oral appliance therapy affects the adverse health consequences of OSAHS $[40,42]$. The hypothesis that successful oral appliance therapy for OSAHS may reduce blood pressure is supported by several studies [57-61]. It has been shown that oral appliance therapy is associated with similarsized reductions as CPAP therapy [57-59].

Adverse effects and complications when initiating oral appliance therapy are generally classified as minor and temporary. They usually comprise transient effects on the craniomandibular and craniofacial complex. When continued, long-term adverse effects of the oral appliances may involve changes in the dental occlusion that need to be monitored for as long as the appliance is used. Both short- and long-term adverse effects may result in treatment discontinuation $[10,43]$.

Although oral appliance therapy usually reduces snoring, it is not always effective in OSAHS patients [33]. Predictors of treatment outcome are, therefore, of importance for selecting suitable patients that may benefit from therapy. Several clinical, upper airway morphological and polysomnographic variables have been reported to correlate with increased effectiveness of oral appliance therapy. A significant shortcoming in the literature is that most of these predictors for treatment outcome of oral appliance therapy are not reported uniformly [38]. In addition, many predictors have not been systematically validated to test their accuracy in a separate population of patients [38]. Therefore, the ability to predict treatment outcome and preselect suitable OSAHS patients for oral appliance therapy is still limited in clinical practice. Despite this shortcoming, oral appliance therapy should be considered more readily in patients with milder OSAHS, more extended maximum mandibular advancement and certain craniofacial characteristics (mandibular retrognathism in particular) [38].

In the past, many upper airway imaging techniques were applied to provide insight in the pathophysiological aspects of SDB. Most of these studies, however, have examined the upper airway in two dimensions, often with static examinations, on awake patients who are upright. The dynamics of the upper airway in an OSAHS patient during sleep are different; as a consequence, dynamic studies should be performed. In recent years, the upper airway has increasingly been studied using a threedimensional approach [41]. Furthermore, computer models were developed using a computational fluid dynamics (CFD) model using raw data from threedimensional computed tomography (CT) images of OSAHS patients. These CFD models allow investigation of the flow characteristics and aerodynamic forces within the upper airway of the OSAHS patient [62]. Recently, such an upper airway model, based on the principles of CFD, that allows visualisation of pharyngeal collapse, has been developed. CT data are transformed and read by the CFD [62]. Preliminary results suggest that the application 


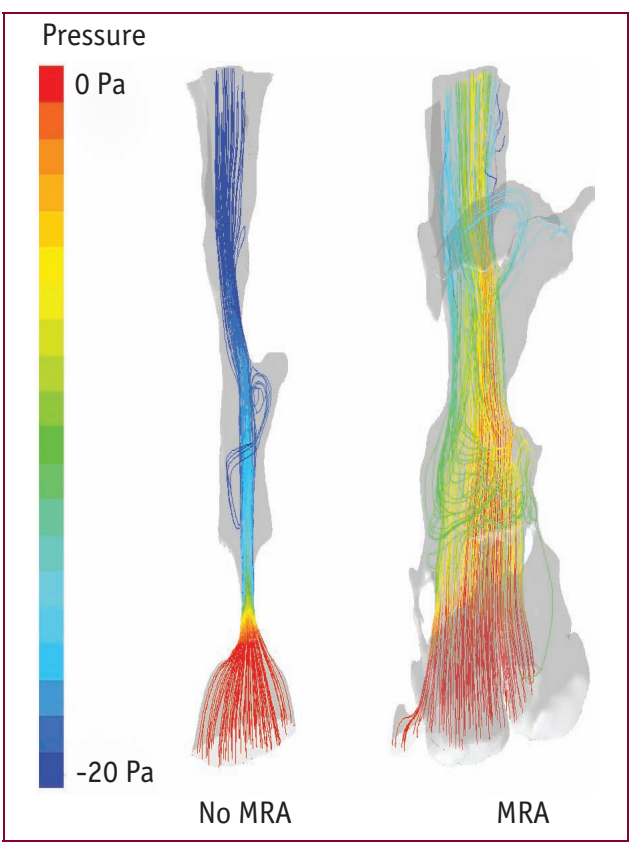

Figure 2

Computational fluid dynamics (CFD) results for a successfully treated patient, where mandibular advancement overcomes local airway narrowing and results in a more homogenous pressure drop over the upper airway. MRA: mandibular repositioning appliance.

of this high-techology upper airway model may have clinical utility for the assessment of treatment success with MRAs for treatment of OSAHS (fig. 2) [42]. Future use of these imaging techniques with CFD calculations, in the selection of patients for OSAHS surgery, has already been suggested $[47,48]$.

\section{Surgical procedures}

Various surgical techniques are available in the treatment of OSAHS. The different surgical methods focus on procedures to treat the three major regions of obstruction in OSAHS patients. Upper airway collapse during sleep can occur at one or more pharyngeal levels, and the majority of OSAHS patients have a multilevel collapse $[30,50-59]$. The three levels of upper airway collapse during SDB are the nasal cavity, retropalatal and retrolingual [30].

Prior to upper airway surgery, the severity of OSAHS should be determined by objective testing $[8,30]$. Evaluation for primary surgery can be considered in patients with mild OSAHS who have surgically correctible anatomical abnormalities, contributing to upper airway collapse during sleep $[8,60]$. There is consensus that surgical procedures are indicated when the outcome of nonsurgical therapies, such as CPAP or oral appliance therapy, is inadequate $[8,61]$. Surgery may also be considered to correct underlying, specific surgically correctable anatomical deficiencies that compromise other therapies or to improve acceptance and tolerance of other OSAHS treatments [8].

Given the fact that, except for maxillomandibular advancement (MMA) surgery, every specific surgical technique targets a specific pharyngeal level, OSAHS patients should be selected by investigating the preoperative pattern of upper airway obstruction [58]. It has been clearly demonstrated that this tailored approach leads to improved surgical results [50, 63-65].

Accurate information regarding the site(s) of upper airway collapse during sleep can be obtained from pharyngeal pressure measurement during sleep studies or fibreoptic images $[50,66,67]$. Alternatively, the site of upper airway obstruction can be assessed by druginduced sleep endoscopy (DISE) $[58,59,63$, 68-72].

Isolated nasal surgery will generally not resolve OSAHS [30]. However, as a decrease in nasal resistance and a reduction in effective CPAP level after nasal surgery might contribute to better CPAP compliance, nasal surgery can be considered in OSAHS patients with nasal obstruction who are not responding to medical treatment, leading to CPAP intolerance $[60,74]$.

Uvulopalatopharyngoplasty (UPPP), introduced by FuנITA et al. [74] in 1981, is the most frequently performed surgical procedure for snoring and OSAHS. By performing UPPP, portions of the palatal edge and the uvula are removed [30]. In unselected patients, the cure rate with UPPP will be low $[30,65]$. UPPP is indicated in carefully selected patients whose site of primary obstruction is at the retropalatal level [30]. Laser assisted uvuloplasty (LAUP) cannot be recommended for the treatment of OSAHS. However, LAUP does appear to be comparable to UPPP for the treatment of snoring $[75,76]$. In addition, the literature does not provide any evidence of a beneficial effect from radiofrequency ablation of the palate on OSAHS [76].

In the case of obstruction of the retrolingual region, volumetric shrinkage of the tongue base by the use of radiofrequency energy might offer a valuable adjunctive procedure [30]. It remains unclear whether a genioglossus advancement (GA) procedure is of additional value in the treatment of OSAHS $[30,64]$. Hyoid myotomy 
and suspension, performed with or without $\mathrm{GA}$, can be part of a multilevel surgery, and might be considered as an alternative and additional technique in well-selected OSAHS patients [30].

MMA surgery in OSAHS patients traditionally consists of a bilateral sagittal split osteotomy of the mandible and a Le Fort I osteotomy of the maxilla (fig. 3) [77]. Advancement of the maxillomandibular complex is suggested to displace the soft tissues attached to the maxilla, mandible and hyoid bone anteriorly [78]. Consequently, enlargement of the velo- and hypopharyngeal airway, and enhanced tension and decreased collapsibility of the pharyngeal dilator musculature may be accomplished. MMA surgery in OSAHS patients generally involves $10 \mathrm{~mm}$ of MMA. A recent systematic review and meta-analysis has shown that, following MMA surgery, the mean apnoea/hypopnoea index (AHI) decreases from 64 to 10 [79]. The pooled surgical success and cure $(\mathrm{AHI}<5)$ rates in this meta-analysis were 86 and $43 \%$, respectively. Younger age, lower preoperative weight and $\mathrm{AHI}$, and greater degree of maxillary advancement were predictive of increased surgical success. The major and minor complication rates were 1.0 and $3.1 \%$, respectively. Most subjects reported satisfaction after MMA, with improvements in quality of life measures and most OSAHS symptomatology. It appears that MRA therapy might be a good predictor for the success of MMA surgery in OSAHS management [79]. Patients with a substantial reduction in baseline AHI with MRA therapy, therefore, appear good candidates for MMA surgery. Moreover, a recent randomised study showed a noninferior success rate when MMA surgery was compared with CPAP [80]. This substantiates the conclusion that MMA surgery is a safe and highly effective treatment modality for OSAHS that should be indicated more readily in clinical practice.

The exact indications for more novel surgical techniques, such as electrical stimulation of the hypoglossal nerve, a tongue anchor for tongue advancement or transoral robotic tongue base resection, are still to be determined, although preliminary results seem to be promising [37-39].

Bariatric surgery is regarded as the most effective treatment for morbid obesity [81]. The degree of benefit, and the rate of morbidity and mortality vary according to the surgical procedure. Several studies of surgical weight loss interventions have shown substantial decreases in OSAHS severity after weight loss [81]. These findings are of major importance for overweight OSAHS patients with poor CPAP compliance [82].

\section{Work-up of the patient that does not tolerate CPAP: need for a multidisciplinary and tailored approach}

As mentioned previously, a proper diagnostic work-up is necessary in every patient with OSAHS referred for reasons of CPAP intolerance. This work-up should include history taking, general clinical examination including measurement of

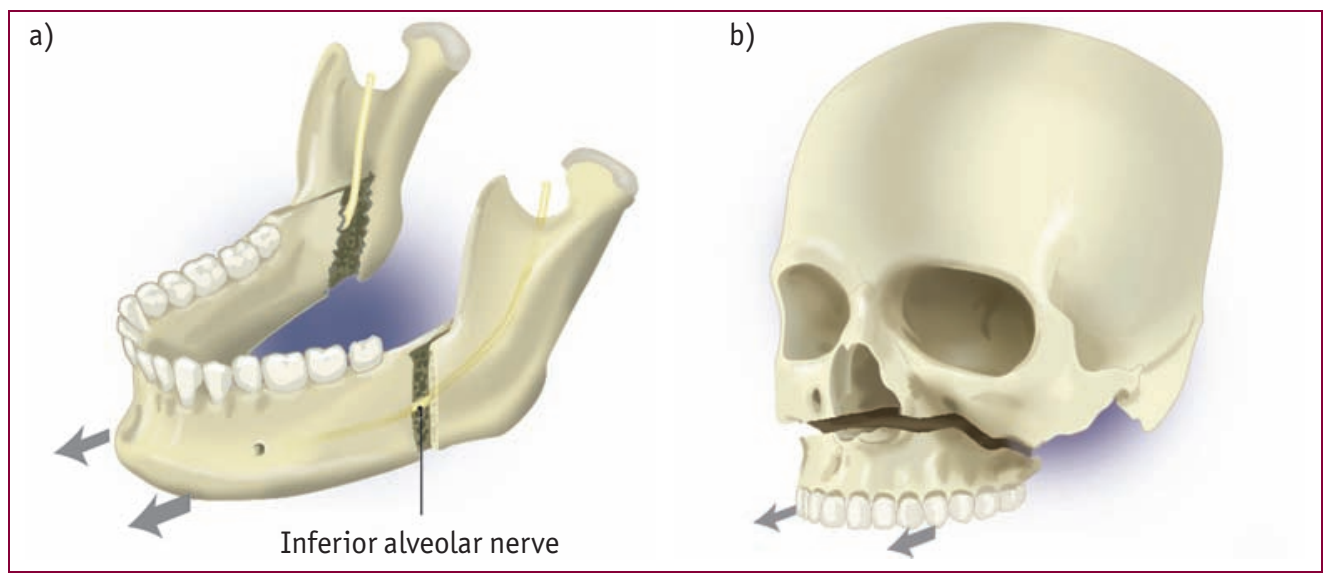

Figure 3

Maxillomandibular advancement (MMA) surgeny in OSAHS patients traditionally consists of a) a bilateral sagittal split osteotomy of the mandible and b) a Le Fort I osteotomy of the maxilla. Adopted from reference [77] with permission from the publisher. 


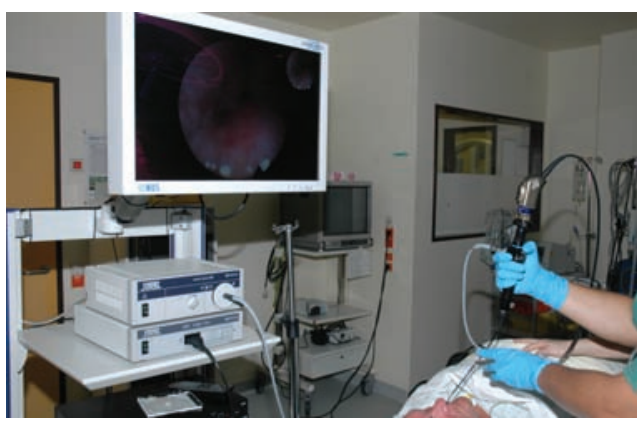

Figure 4

The drug-induced sleep endoscopy (DISE) procedure is performed by an ear, nose and throat surgeon in the operating theatre with the patient in the supine position; the DISE procedure is recorded digitally. blood pressure and body mass index, an oral and maxillofacial evaluation, and a clinical ear, nose and throat (ENT) examination including fibre-optic endoscopic evaluation of the upper airways [60].

In the work-up of possible candidates for oral appliance therapy, a multidisciplinary approach is mandatory, with the strict need for excellent cooperation between the ENT surgeon, the sleep physician and a "dental sleep professional", a dental practitioner with expertise in dental sleep medicine [13].

In making a surgical decision, additional information regarding the site(s) of upper airway collapse should be obtained pre-operatively.
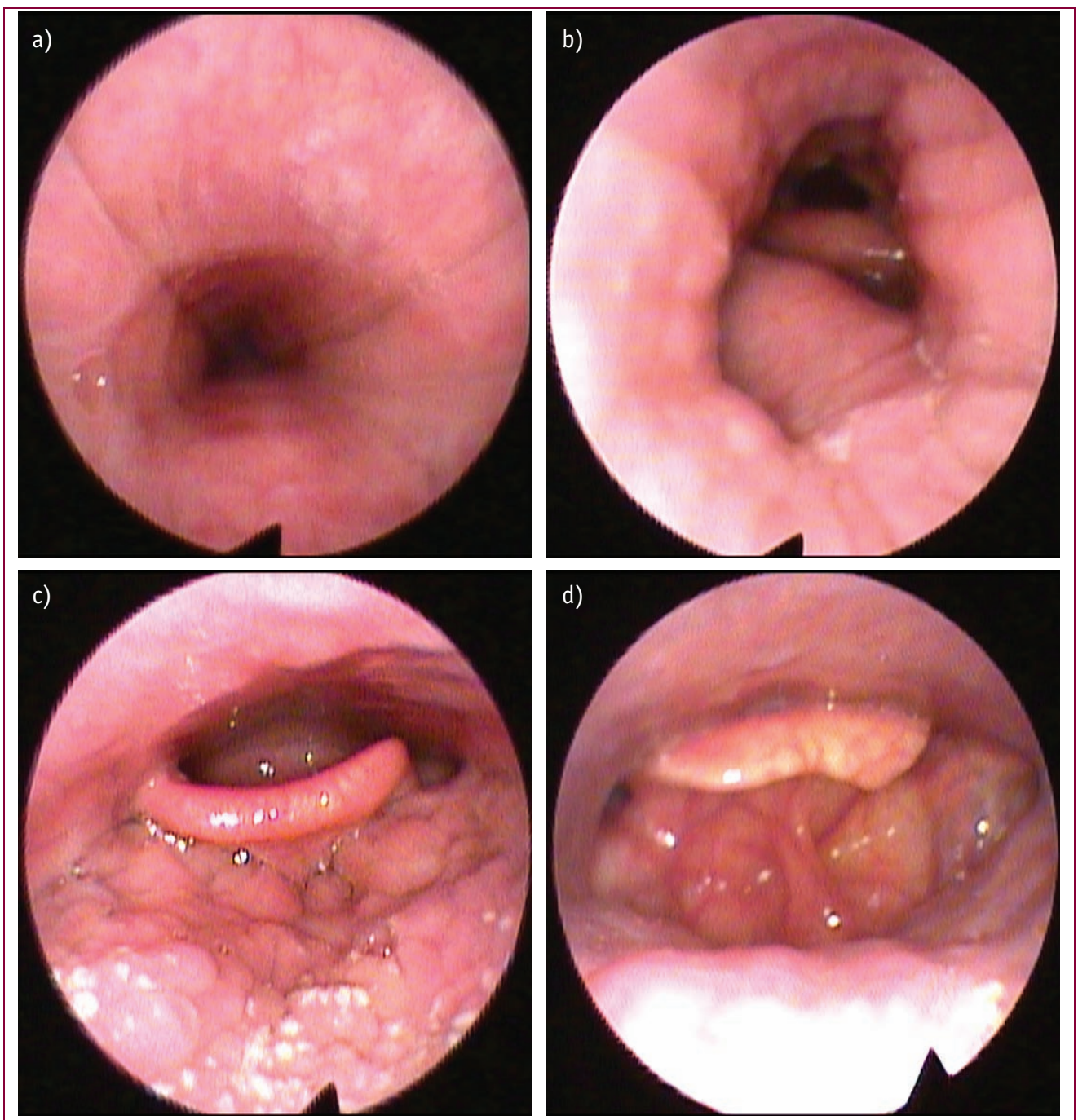

Figure 5

Some examples of patterns of upper airway collapse as documented by drug-induced sleep endoscopy: a) circular palatal collapse; b) laterolateral oropharyngeal collapse; c) anteroposterior collapse at the level of the tongue base; and d) anteroposterior collapse of the epiglottis. 
The fact that OSAHS patients have a higher risk for for pre, peri- and postoperative complications when having surgery under general anesthesia is an important factor in surgical decision-making $[83,84]$. Moreover, these risks should be discussed preoperatively with the patient [85].

Sleep nasendoscopy or DISE was first described in 1991 by CROF and PRINGLE [69]. The technique of DISE requires pharmacologic induction of artificial sleep, either by midazolam and/ or propofol $[72,86]$. During DISE, the upper airway is visualised using a flexible fibre-optic nasopharyngoscope, providing a direct observation of the localisation of the flutter and collapse during snoring and sleep apnoea that occurs during drug-induced sleep. The DISE procedure is performed by an ENT surgeon in the operating theatre (fig. 4). The different regions of the upper airway that are investigated during DISE are the levels of the velopharynx (palate), oropharynx, tongue base and epiglottis. At each of these pharyngeal levels, the degree of collapse is reported as complete, partial or none. The pattern of the obstruction is described as being concentric, anteroposterior or laterolateral [60, 86]. Examples of different types of upper airway collapse, as documented during DISE, are seen in figure 5 .

It has been demonstrated that the success rate of UPPP increases when including DISE in the diagnostic workup [63]. DISE has also been suggested as a valuable prognostic indicator of successful MRA treatment in the individual patient $[68,87]$.

\section{Conclusions}

CPAP is regarded the treatment of choice for OSAHS patients with moderate-to-severe OSAHS. The clinical success of CPAP is, however, limited by the fact that not all patients can tolerate CPAP treatment or are compliant with it. Efficacious alternative therapies include oral appliance therapy and surgical procedures. Future use of high-technology upper airway models based on CT scan and CFD has clinical utility for the assessment of treatment success of these nonCPAP therapies for OSAHS. In addition, it has been demonstrated that, by adding DISE to the diagnostic workup of the OSAHS patient, the success rate of both upper airway surgery and oral appliance therapy increases significantly.

\section{Reference List}

1. American Academy of Sleep Medicine. International Classification of Sleep Disorders: Diagnostic and Coding Manual, 2nd Edn. Rochester, American Academy of Sleep Medicine, 2005.

2. Young T, Palta M, Dempsey J, et al. The occurrence of sleep-disordered breathing among middle-aged adults. N Engl J Med 1993; 328: 1230-1235.

3. Kiely JL, McNicholas WT. Cardiovascular risk factors in patients with obstructive sleep apnoea syndrome. Eur Respir J 2000; 16: 128-133.

4. Young T, Peppard PE, Gottlieb DJ. Epidemiology of obstructive sleep apnea: a population health perspective. Am J Respir Crit Care Med 2002; 165: 1217-1239.

5. Parra 0, Arboix A, Montserrat JM, et al. Sleep-related breathing disorders: impact on mortality of cerebrovascular disease. Eur Respir J 2004; 24: 267-272.

6. Yaggi HK, Concato J, Kernan WN, et al. Obstructive sleep apnea as a risk factor for stroke and death. N Engl J Med 2005; 353: 2034-2041.

7. McNicholas WT, Bonsignore MR. Sleep apnoea as an independent risk factor for cardiovascular disease: current evidence, basic mechanisms and research priorities. Eur Respir J 2007; 29: 156-178.

8. Epstein LJ, Kristo D, Strollo PJ Jr, et al. Clinical guideline for the evaluation, management and long-term care of obstructive sleep apnea in adults. J Clin Sleep Med 2009; 5: 263-276.

9. Sullivan CE, Issa FG, Berthon-Jones M, et al. Reversal of obstructive sleep apnoea by continuous positive airway pressure applied through the nares. Lancet 1981; 1: 862-865.

10. Marklund M. Oral Appliances in the treatment of obstructive sleep apnea and snoring, In: Randerath WJ, Sanner BM, Somers VK, eds. Sleep Apnea. Basel: Karger, 2006; 151-159.

11. Kushida CA, Morgenthaler TI, Littner MR, et al. Practice parameters for the treatment of snoring and obstructive sleep apnea with oral appliances: an update for 2005. Sleep 2006; 29: 240-243.

12. Vanderveken OM, Devolder A, Marklund M, et al. Comparison of a custom-made and a thermoplastic oral appliance for the treatment of mild sleep apnea. Am J Respir Crit Care Med 2008; 178: 197-202.

13. Chan AS, Cistulli PA. Oral appliance treatment of obstructive sleep apnea: an update. Curr Opin Pulm Med 2009; 16: 591-596.

14. Bradley TD, Floras JS. Obstructive sleep apnoea and its cardiovascular consequences. Lancet 2009; 373: 82-93.

15. Li KK, Powell NB, Riley RW, et al. Morbidly obese patients with severe obstructive sleep apnea: is airway reconstructive surgery a viable treatment option? Laryngoscope 2000; 110: 982-987.

16. Sundaram S, Bridgman SA, Lim J, et al. Surgery for obstructive sleep apnoea. Cochrane Database Syst Rev 2005; 4: CD001004.

17. McMains KC, Terris DJ. Evidence-based medicine in sleep apnea surgery. Otolaryngol Clin North Am 2003; 36: 539561.

\section{Educational questions}

True or false:

1. Active

temporomandibular

dysfunction is an absolute

contraindication for MRA

treatment.

2. CPAP remains the

treatment of choice for

patients with moderateto-

severe OSAHS.

3. The use of DISE in the diagnostic workup of the OSAHS patient does not lead to a significant increase of the success rate of UPPP.

4. Patients with severe OSAHS, who have failed CPAP therapy, are not good candidates for MRA treatment.

5. Successful MRA therapy might be a good predictor for the success of MMA surgery in OSAHS management.

6. The majority of OSAHS patients have a unilevel pharyngeal collapse. 
18. Smith IE. Alternative therapies for obstructive sleep apnea syndrome: behavioral and pharmacological options, In: Randerath WJ, Sanner BM, Somers VK, eds. Sleep Apnea - Current Diagnosis and Treatment. Basel: S. Karger AG, 2006; 174-179.

19. Ballester E, Badia JR, Hernandez L, et al. Evidence of the effectiveness of continuous positive airway pressure in the treatment of sleep apnea/hypopnea syndrome. Am J Respir Crit Care Med 1999; 159: 495-501.

20. Giles TL, Lasserson TJ, Smith BJ, et al. Continuous positive airways pressure for obstructive sleep apnoea in adults. Cochrane Database Syst Rev 2006; 1: CD001106.

21. Gordon P, Sanders MH. Sleep.7: positive airway pressure therapy for obstructive sleep apnoea/hypopnoea syndrome. Thorax 2005; 60: 68-75.

22. Montserrat JM, Ferrer M, Hernandez L, et al. Effectiveness of CPAP treatment in daytime function in sleep apnea syndrome: a randomized controlled study with an optimized placebo. Am J Respir Crit Care Med 2001; 164: 608613.

23. Lindberg E, Berne C, Elmasry A, et al. CPAP treatment of a population-based sample - what are the benefits and the treatment compliance? Sleep Med 2006; 7: 553-560.

24. Amfilochiou A, Tsara V, Kolilekas L, et al. Determinants of continuous positive airway pressure compliance in a group of Greek patients with obstructive sleep apnea. Eur J Intern Med 2009; 20: 645-650.

25. De Backer W. Non-CPAP treatment of obstructive sleep apnoea. Monaldi Arch Chest Dis 1998; 53: 625-629.

26. Grote L, Hedner J, Grunstein R, et al. Therapy with nCPAP: incomplete elimination of Sleep Related Breathing Disorder. Eur Respir J 2000; 16: 921-927.

27. Olson EJ, Moore WR, Morgenthaler TI, et al. Obstructive sleep apnea-hypopnea syndrome. Mayo Clin Proc 2003; 78: $1545-1552$.

28. Chervin RD, Theut S, Bassetti C, et al. Compliance with nasal CPAP can be improved by simple interventions. Sleep 1997; 20: 284-289.

29. Ryan S, Doherty LS, Nolan GM, et al. Effects of heated humidification and topical steroids on compliance, nasal symptoms, and quality of life in patients with obstructive sleep apnea syndrome using nasal continuous positive airway pressure. J Clin Sleep Med 2009; 5: 422-427.

30. Powell NB. Contemporary surgery for obstructive sleep apnea syndrome. Clin Exp Otorhinolaryngol 2009; 2: 107114.

31. Ayas NT, FitzGerald JM, Fleetham JA, et al. Cost-effectiveness of continuous positive airway pressure therapy for moderate to severe obstructive sleep apnea/hypopnea. Arch Intern Med 2007; 166: 977-984.

32. Pelletier-Fleury N, Meslier N, Gagnadoux F, et al. Economic arguments for the immediate management of moderateto-severe obstructive sleep apnoea syndrome. Eur Respir J 2004; 23: 53-60.

33. Lankford DA, Proctor CD, Richard R. Continuous positive airway pressure (CPAP) changes in bariatric surgery patients undergoing rapid weight loss. Obes Surg 2005; 15: 336-341.

34. Smith I, Lasserson TJ. Pressure modification for improving usage of continuous positive airway pressure machines in adults with obstructive sleep apnoea. Cochrane Database Syst Rev 2009; 4: CD003531.

35. Denbar MA. A case study involving the combination treatment of an oral appliance and auto-titrating CPAP unit. Sleep Breath 2002; 6: 125-128.

36. Gotsopoulos H, Kelly JJ, Cistulli PA. Oral appliance therapy reduces blood pressure in obstructive sleep apnea: a randomized, controlled trial. Sleep 2004; 27: 934-941.

37. Schwartz AR, Bennett ML, Smith PL, et al. Therapeutic electrical stimulation of the hypoglossal nerve in obstructive sleep apnea. Arch Otolaryngol Head Neck Surg 2001; 127: 1216-1223.

38. Vicini C, Dallan I, Canzi P, et al. Transoral robotic tongue base resection in obstructive sleep apnoea-hypopnoea syndrome: a preliminary report. ORL J Otorhinolaryngol Relat Spec 2010; 72: 22-27.

39. Hamans E, Boudewyns A, Stuck BA, et al. Adjustable tongue advancement for obstructive sleep apnea: a pilot study. Ann Otol Rhinol Laryngol 2008; 117: 815-823.

40. Tsai WH, Vazquez JC, Oshima T, et al. Remotely controlled mandibular positioner predicts efficacy of oral appliances in sleep apnea. Am J Respir Crit Care Med 2004; 170: 366-370.

41. Schwab RJ, Pasirstein M, Pierson R, et al. Identification of upper airway anatomic risk factors for obstructive sleep apnea with volumetric magnetic resonance imaging. Am J Respir Crit Care Med 2003; 168: 522-530.

42. De Backer JW, Vanderveken OM, Vos WG, et al. Functional imaging using computational fluid dynamics to predict treatment success of mandibular advancement devices in sleep-disordered breathing. J Biomech 2007; 40: 37083714.

43. Ferguson KA, Cartwright R, Rogers R, et al. Oral appliances for snoring and obstructive sleep apnea: a review. Sleep 2006; 29: 244-262.

44. Hoekema A, Stegenga B, De Bont LG. Efficacy and co-morbidity of oral appliances in the treatment of obstructive sleep apnea-hypopnea: a systematic review. Crit Rev Oral Biol Med 2004; 15: 137-155.

45. Chan AS, Cistulli PA. Oral appliance treatment of obstructive sleep apnea: an update. Curr Opin Pulm Med 2009; 16: 591-596.

46. Randerath WJ, Heise M, Hinz R, et al. An individually adjustable oral appliance vs continuous positive airway pressure in mild-to-moderate obstructive sleep apnea syndrome. Chest 2002; 122: 569-575.

47. Huang Y, White DP, Malhotra A. Use of computational modeling to predict responses to upper airway surgery in obstructive sleep apnea. Laryngoscope 2007; 117: 648-653.

48. Yu CC, Hsiao HD, Lee LC, et al. Computational fluid dynamic study on obstructive sleep apnea syndrome treated with maxillomandibular advancement. J Craniofac Surg 2009; 20: 426-430.

49. Smith DM, Stradling JR. Can mandibular advancement devices be a satisfactory substitute for short term use in patients on nasal continuous positive airway pressure? Thorax 2002; 57: 305-308.

50. Boudewyns AN, De Backer WA, Van de Heyning PH. Pattern of upper airway obstruction during sleep before and after uvulopalatopharyngoplasty in patients with obstructive sleep apnea. Sleep Med 2001; 2: 309-315.

51. Petit FX, Pepin JL, Bettega G, et al. Mandibular advancement devices: rate of contraindications in 100 consecutive obstructive sleep apnea patients. Am J Respir Crit Care Med 2002; 166: 274-278.

52. Hoekema A, de Vries F, Heydenrijk K, et al. Implant-retained oral appliances: a novel treatment for edentulous patients with obstructive sleep apnea-hypopnea syndrome. Clin Oral Implants Res 2007; 18: 383-387.

53. Lowe AA. Oral appliances for sleep breathing disorders, In: Kryger MH, Roth T, Dement WC, eds. Principles and Practice of Sleep Medicine, 3rd Edn. Philadelphia: W.B. Saunders Company, 2000; 929-939. 
54. Petelle B, Vincent G, Gagnadoux F, Rakotonanahary D, Meyer B, Fleury B. One-night mandibular advancement titration for obstructive sleep apnea syndrome: a pilot study. Am J Respir Crit Care Med 2002; 165(8): 1150-1153.

55. Horner RL, Bradley TD. Update in sleep and control of ventilation 2008. Am J Respir Crit Care Med 2009; 179: 528532.

56. Vanderveken 0M, Devolder A, Marklund M, et al. Comparison of a custom-made and a thermoplastic oral appliance for the treatment of mild sleep apnea. Am J Respir Crit Care Med 2008; 178: 197-202.

57. Hamans $E$, Meeus 0 , Boudewyns $A$, et al. Outcome of sleep endoscopy in obstructive sleep apnoea: the Antwerp experience. B-ENT 2010; 6: 97-103.

58. Rodriguez-Bruno K, Goldberg AN, McCulloch CE, et al. Test-retest reliability of drug-induced sleep endoscopy. Otolaryngol Head Neck Surg 2009; 140: 646-651.

59. Boudewyns AN, Van de Heyning PH, De Backer WA. Site of upper airway obstruction in obstructive apnoea and influence of sleep stage. Eur Respir J 1997; 10: 2566-2572.

60. Boudewyns AN, Vanderveken OM, Hamans EH, et al. Surgery for obstructive sleep apnoea: an otorhinolaryngologist's perspective. Int J Respir Care 2006; 4: 123-129.

61. American Sleep Disorders Association. Practice parameters for the treatment of obstructive sleep apnea in adults: the efficacy of surgical modifications of the upper airway. Report of the American Sleep Disorders Association. Sleep 1996; 19: 152-155.

62. Vos W, De Backer J, Devolder A, et al. Correlation between severity of sleep apnea and upper airway morphology based on advanced anatomical and functional imaging. J Biomech 2007; 40: 2207-2213.

63. Hessel NS, Vries N. Results of uvulopalatopharyngoplasty after diagnostic workup with polysomnography and sleep endoscopy: a report of 136 snoring patients. Eur Arch Otorhinolaryngol 2003; 260: 91-95.

64. Richard W, Kox D, den Herder C, et al. One stage multilevel surgery (uvulopalatopharyngoplasty, hyoid suspension, radiofrequent ablation of the tongue base with/without genioglossus advancement), in obstructive sleep apnea syndrome. Eur Arch Otorhinolaryngol 2007; 264: 439-444.

65. Sher AE, Schechtman KB, Piccirillo JF. The efficacy of surgical modifications of the upper airway in adults with obstructive sleep apnea syndrome. Sleep 1996; 19: 156-177.

66. Morrell MJ, Arabi Y, Zahn B, et al. Progressive retropalatal narrowing preceding obstructive apnea. Am J Respir Crit Care Med 1998; 158: 1974-1981.

67. Badr MS, Toiber F, Skatrud JB, et al. Pharyngeal narrowing/occlusion during central sleep apnea. J Appl Physiol 1995; 78: 1806-1815.

68. Battagel JM, Johal A, Kotecha BT. Sleep nasendoscopy as a predictor of treatment success in snorers using mandibular advancement splints. J Laryngol Otol 2005; 119: 106-112.

69. Croft CB, Pringle M. Sleep nasendoscopy: a technique of assessment in snoring and obstructive sleep apnoea. Clin Otolaryngol Allied Sci 1991; 16: 504-509.

70. den Herder C, van Tinteren H, de Vries N. Sleep endoscopy versus modified Mallampati score in sleep apnea and snoring. Laryngoscope 2005; 115: 735-739.

71. Hessel NS, de Vries N. Diagnostic work-up of socially unacceptable snoring. II. Sleep endoscopy. Eur Arch Otorhinolaryngol 2002; 259: 158-161.

72. Kezirian EJ, White DP, Malhotra A, et al. Interrater reliability of drug-induced sleep endoscopy. Arch Otolaryngol Head Neck Surg 2010; 136: 393-397.

73. Friedman M, Tanyeri H, Lim JW, et al. Effect of improved nasal breathing on obstructive sleep apnea. Otolaryngol Head Neck Surg 2000; 122: 71-74.

74. Fujita S, Conway W, Zorick F, et al. Surgical correction of anatomic abnormalities in obstructive sleep apnea syndrome: uvulopalatopharyngoplasty. Otolaryngol Head Neck Surg 1981; 89: 923-934.

75. Littner M, Kushida CA, Hartse K, et al. Practice parameters for the use of laser-assisted uvulopalatoplasty: an update for 2000. Sleep 2001; 24: 603-619.

76. Franklin KA, Anttila H, Axelsson S, et al. Effects and side-effects of surgery for snoring and obstructive sleep apnea: a systematic review. Sleep 2009; 32: 27-36.

77. Rosenberg AJ, Damen GW, Schreuder KE, et al. [Obstructive sleep-apnoea syndrome: good results with maxillomandibular osteotomy after failure of conservative therapy]. Ned Tijdschr Geneeskd 2005; 149: 1223-1226.

78. Hoekema A, de Lange J, Stegenga B, et al. Oral appliances and maxillomandibular advancement surgery: an alternative treatment protocol for the obstructive sleep apnea-hypopnea syndrome. J Oral Maxillofac Surg 2006; 64: 886-891.

79. Holty JE, Guilleminault C. Maxillomandibular advancement for the treatment of obstructive sleep apnea: a systematic review and meta-analysis. Sleep Med Rev 2010; 14: 287-297.

80. Vicini C, Dallan I, Campanini A, et al. Surgery vs ventilation in adult severe obstructive sleep apnea syndrome. Am J Otolaryngol 2010; 31: 14-20.

81. Fritscher LG, Mottin CC, Canani S, et al. Obesity and obstructive sleep apnea-hypopnea syndrome: the impact of bariatric surgery. Obes Surg 2007; 17: 95-99.

82. Young T, Skatrud J, Peppard PE. Risk factors for obstructive sleep apnea in adults. JAMA 2004; 291: 2013-2016.

83. Esclamado RM, Glenn MG, McCulloch TM, et al. Perioperative complications and risk factors in the surgical treatment of obstructive sleep apnea syndrome. Laryngoscope 1989; 99: 1125-1129.

84. den Herder C, Schmeck J, Appelboom DJ, et al. Risks of general anaesthesia in people with obstructive sleep apnoea. BMJ 2004; 329: 955-959.

85. Connolly LA. Anesthetic management of obstructive sleep apnea patients. J Clin Anesth 1991; 3: 461-469.

86. Pringle MB, Croft CB. A grading system for patients with obstructive sleep apnoea based on sleep nasendoscopy. Clin Otolaryngol Allied Sci 1993; 18: 480-484.

87. Johal A, Battagel JM, Kotecha BT. Sleep nasendoscopy: a diagnostic tool for predicting treatment success with mandibular advancement splints in obstructive sleep apnoea. Eur J Orthod 2005; 27: 607-614.

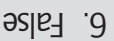

วกц $\mathrm{S}$

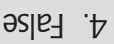

כ'

วกц $\tau$

วาม 'L

sıәмsue рә7รәббпns 